\title{
Periscope.
}

January 29th. On the 13 th a cyclonic centre passed nearly over or a little to the $\mathrm{N}$. of this city-rain fell heavily (at Kingstown 95 inch, in Dublin $\cdot 83$ inch, and in the Phonix Park $\cdot 66$ inch), and the wind shifted from E.S.E. to W.S.W. with a fall of temperature. Heavy sleet, snow, and hail fell subsequently. Very mild open weather soon set in, and continued to the end of the month. On the 17 th a clear sky and warm sun sent the thermometer up to $594^{\circ}$ in the shade. A second anticyclone formed on the 18th, and the barometer rose to $30 \cdot 673$ inches by the evening of the 21 st. Pressure gave way considerably during the last few days, so that on the 27 th the reading of 29.502 inches was recorded. At 315 p.m. of the 15 th a severe hail-shower passed across Dublin with "festooned" clouds. The mean temperature was the same as that of February, 1877 , but about $2^{\circ}$ above that of the corresponding month in the previous ten years.

PERISCOPE.

Edited by G. F. Doffex, M.D., F.K.Q.C.P.

\section{WRITER'S CRAMP.}

M. Gallard, in his recent volume, Clinique Médicale de la Pitié, has come to the conclusion that writer's cramp is certainly a professional disease, but a clinical study of it decidedly shows that it is far from being special to persons who write much. Absolutely similar disturbances are seen in persons who follow other avocations, such as engravers, artificial flower-makers, pianists, violinists, telegraphists who use the house-telegraph, \&c. But in all these persons the disturbances observed occur in the hands and fingers. Absolutely similar-nay, identical disturbances are observed in persons following professions which exercise other muscles than those of the forearm or hand; and then these disturbances occur in the muscles which are necessarily contracted by the habitual exercise of the avocation, whether these muscles be those of the arm, shoulder, leg, neck, face, or even the trunk. The analysis of these various facts leads the writer to the first conclusion, that the disease in question is not peculiar to writers; the analysis of the symptoms leads him to another conclusion, that it is not a cramp; whence he feels the necessity of substituting for the incorrect denomination writer's cramp, the far more suitable name proposed by Dr. Duchenne of Boulogne-viz., functional impotence. In reference to establishing the nature of this morbid condition, M. Gallard, after having proved that it evades any anatomical localisation whatever, is led to admit that it is a simple functional disturbance and nothing else. He is particularly struck by finding, with regard to its etiology, that fatigue is 
far from being an essential cause of it; for this disease does not occur in those who work in a certain way, when the intelligence, otherwise occupied, does not exercise a sufficiently attentive supervision over the muscular movements. 'This is because there is at that time a veritable discordance between the cerebral acts and the movements, which are performed in a thoroughly automatic manner, that the muscles become fatigued, and finish by performing disordinate movements, that they may be considered as being in an ataxic condition. It is very singular to see a trouble so essentially nervous constitute a morbid functional state which is almost incurable; and M. Gallard in vain seeks the reason of this peculiarity in certain diathetic influences, which he most carefully studies, and which he endeavours to make the basis of a rational treatment. But he is obliged to acknowledge the small efficacy of all the medical means he has successively employed, including electricity; and, tired of the struggle, is reduced to advise prothetic apparatus, in which he does not seem to have much more confidence, although he describes them with great minuteness.—Lond. Med. Recurd, Jan. 15, 1878.

\section{CAFFEINE IN CEPHALALGIA.}

Citrate of caffeine in doses of two grains every half hour until the pain ceases is strongly adrocated as an effectual remedy. Often one or two doses are quite sufficient. The only contra-indication is sleeplessness, which sometimes results if it is taken in the evening. It is preferable to guarana as being hardly ever rejected by the stomach. In hay-fever, spinal irritation, and general neuralgia, it would seem worthy of a trial.Montpellier Médical.

S. W.

\section{INJECTION OF ACETIC ACID IN CANCEROUS TISSUE.}

A MAN, sixty-two years of age, was attacked by a carcinoma of the left horizontal part of the inferior maxilla. Siome years before an indurated kernel had been excised from his lower lip. Soon after the operation he complained of lancinating pains in the tongue. The cause was found to be a cancerous abscess, developed in the left half of this organ, near the epiglottis. This new formation was likewise extirpated; to accomplish it, it was necessary to tie, beforehand, the lingual artery and to divide the maxilla. After seven months two other tumours showed themselvesone, small and indurated, on the lower border of the left maxilla; the other, larger and softer, more towards the front of the neck; the last shrank under the influence of applications of ice; the first remained stationary. A year after the extirpation of the tongue there appeared, in the neighbourhood of the right submaxillary gland, another tumour of rapid growth, which resisted the ice treatment. This tumour was likewise a cancer, a microscopic examination being made of a piece extracted by the small harpoon. Into this Dr. Geiss injected, daily, for 
a week, acetic acid by means of a Pravaz syringe. The first injection was of the strength of 2 in 9, afterwards it was raised to 1 in 3 . Each time the injection was made by a single opening in the skin, but the syringe was turned in several directions, so that the contents of the syringe might traverse a large extent of the tumour. A sharp inflammation followed. On the tenth day a deep incision was made by a bistoury, and a drainage tube introduced, giving vent to a very fœtid, sanious fluid. At the end of seventeen days the suppuration ceased, and there remained only a kernel about the size of a walnut. Soon afterwards four injections were made in the small tumour, on the border of the maxilla, and in a new one which had become developed in the cheek. A fresh tumour took its rise behind the left ear ; it became the size of a hen's egg, very hard, and the microscopic examination showed a fibrocellular stroma, as in the first. Injections were employed, and the author injected every day with two or three syringes, so that in eleven days twenty-five syringefuls of acetic acid solution were used. The first set of injeetions had provoked no pain-these, on the contrary, were very painful, and were followed by an abundant suppuration, which lasted three weeks, and the tumour completely disappeared. Like success was obtained in the case of a lady who had a cancerous tumour of the breast, the size of a hen's egg, and who would not submit to have it excised. For ten days injections were made; on the eleventh day it was incised. The suppuration ceased at the end of fifteen days, and in four weeks' time there was only a kernel of the size of a nut. The author believes that these injections of concentrated acetic acid will at least hinder the rapid development of many forms of malignant disease, and, in some cases, effect a radical cure.-Deutsche Zeitschrift für Chirurgie and Revue Médicale.

S. W.

\section{IODIC PURPERA.}

IN that excellent new French periodical, the Revue Mensuelle, for September, M. Fournier describes a rash consisting in the production of small spots, presenting the characters of purpura which followed the administration of the iodide of potassium. M. Fournier publishes the notes of three apparently conclusive cases, in which this eruption was connected with the medicinal use of the iodide, disappearing when it was ceased. More Gallico he sums up as follows:-1. The internal use of the iodide of potassium causes, in some cases, a petechial eruption deserving the name of iodic purpura, or petechial iodism. 2. The purpura is seated nearly constantly upon the legs and on their anterior aspect. It is always discreet, and composed of small sanguineous miliary spots, not causing any local or general disorder, remaining, for that very reason, latent, and disappearing spontaneously in a space of time varying from two to three weeks. 3 . It is a rare phenomenon, only 
produced in certain patients peculiarly predisposed by natural idiosyncrasy, and particularly liable, in this same class of invalids, to relapses.

[M. Fournier is in error if he believes that he is the first to describe this peculiar medicinal rash. His distinguished master, Ricord, observed it, as have also Bumstead, the well-known American syphilographer; Virchow, and Ringer. References to the cases described by these authorities will be found in Dr. Walter Smith's " Reports on Materia Medica and Therapeutics" in this Journal for Aug., 1871 ; Feb., 1872 ; and Feb., 1873. In Ringer's case iodide of potassium or iodide of ammonium produced purpura, but iodide of sodium did not.-ED., Periscope.]

\section{NEW FORM OF SPHYGMOGRAPH.}

IN the October number of the Journal of Anatomy and Physiology for last year, Dr. W. J. Fleming, of Glasgow, describes a form of transmission sphygmograph which he has devised. A curved brass plate passes down over the front of the wrist into the hollow of the hand. This is held in position by three lead bands. The wrist being placed horizontally on a cushion, a Marey's tambour may be brought vertically over the radial artery, and lowered until a rod, perpendicular to its surface, comes to press with its terminal button to any desired degree on the vessel. By means of a series of split weights any given pressure may be applied. The ease and accuracy with which the instrument can be adjusted, the absence of springs, and the non-occurrence of extraneous pressure on the vessels, are among the advantages claimed by the author for this instrument.

R. J. H.

AMPUTATION AT THE HIP-JOINT.

The latest statistics, we believe, that have appeared of amputation at the hip-joint are by Dr. August Lüling, and are given in the Deutsche Zeitschrift für Chirurgie, Vol. VIII., page 327 (June 15, 1877). They are as follows:-

\begin{tabular}{|c|c|c|c|c|c|}
\hline Traumatic, & & & \multicolumn{3}{|c|}{ Mortality, 85 per cent. } \\
\hline Gunshot traumatic, & & & $\eta$ & 88 & \\
\hline Pathological, & $\bullet$ & & $\eta$ & 42 & " \\
\hline Re-amputation, & - & • & $\eta$ & 40 & " \\
\hline After previous resect & & $\cdot$ & , & 50 & " \\
\hline General mortality in & $80 \mathrm{ca}$ & & , & 70 & " \\
\hline
\end{tabular}

Of 239 fatal cases, $5 \frac{1}{2}$ per cent. died during the operation; $12 \frac{1}{2}$ per cent. during the first hour; 26 per cent. in the course of 5 hours- 5 of these from chloroform; 46 per cent. in 24 hours. Eighteen cases died from pyæmia, 70 per cent. in 5 days. Eight times death followed from secondary hæmorrhage. [The above figures are taken from a report by Dr. Erskine Mason, of New York, of his third successful case of this kind, in the N. Y. Med. Jour. of February, 1878.] 
entirely engaged in out-door pursuits, and lead an active life, and are, as a rule, a hardy race; but the cause I think can be found in the enormous quantities of tea consumed, and especially in the fact that it is generally drunk at a very high temperatnre. I think there can be no doubt that the habit of drinking fluids either very hot or very cold is a fruitful cause of dyspepsia, such fluids acting as stimulants to the mucous membrane of the stomach, and when often applied bringing it into a state of chronic congestion-the prevalence of dyspeptic disorders among our American cousins, who imbibe such quantities of iced water, being a further confirmation of this fact.

These are the principal remarks I have to offer; and I would say, in conclusion, that any one going out to Newfoundland for a summer voyage will find it most enjovable, and will meet with a hearty hospitality from all ranks of society there-and, if a sporting man, will be fully able to gratify his tastes in that respect.

TREATMENT OF DIABETES MELlitus WITH SALICYLATE OF SODA.

RYBA and Plumert have arrived at the following results:-1. Salicylate of soda, given in daily doses of eight grammes, determined a decided diminution of saccharine excretion. 2. Considerable differences are observed, according to the severity of the case. In recent cases the sugar can be made to disappear completely, and does not reappear immediately after the remedy is stopped. In cases of longer duration, the effectiveness of the remedy is also apparent, though the sugar does not disappear entirely, nor is there a favourable after-effect. Lastly, in cases of several years' duration, with severe diabetic symptoms, no result was attained by treatment, at least not from the small doses administered. 3. The diminution of saccharine production is more remarkable by the greatest restriction of hydrocarbons in the diet. 4. Diminution of the quantity of urine is parallel with the diminution of sugar; but in one case the polyuria remained in spite of the considerable diminution of saccharine excretion. Other diabetic symptoms, and the bodily weight, are also favourably influenced. 5. In two cases the quantity of both urine and sugar was increased for a short time after the commencement of medication, followed, however, by progressive diminution. Treatment by salicylate of soda is followed by a greater diminution of sugar excreted than when the treatment is indifferent.-Präger Med. Woch. and N. Y. Med. Jour., Feb. 1878. 
muscles until it is felt to react under the stimulus thus applicd; he disapproves of the method of producing muscular contraction by friction longitudinally on the skin. In weakly people, despite the exposure to the air it involves, this process raises the general temperature $\frac{1}{2}^{\circ}$ to $1 \frac{1}{2}^{\circ}$ Fahr., according to Dr. Weir Mitchell. In a case of extreme anæmia, with debility, emaciation, \&c., the latter physician obtained a most successful result where every method of treatment previously tried had failed, by combining absolute rest (which alone had also failed) with massage and the induction current. "At first, as always, the extremities became cold under massage, then they grew warm, and at last, when she was well, the massage no longer elevated her temperature. And this is the rule."

Dr. Douglas Graham (New York Medical Record, April 28, 1877 ) reports several cases of muscular trouble from over-exercise of certain sets of muscles, and one or two of incipient writers' cramp, that were cured or materially benefited by massage. In one case, that of a pianist, it was of no benefit as far as applied.

ENGLISH SEASIDE WINTER HEALTH RESORTS.

At the usual monthly meeting of the Meteorological Society, London, held on Wednesday, Feb. 20th, at the Institution of Civil Engineers, Mr. C. Greaves, F.G.S., President, in the chair, Dr. Tripe read a paper on "The Winter Climate of some English Seaside Health Resorts." The places selected were Scilly, Torquay, Penzance, Guernsey, Barnstaple, Ventnor, Llandudno, Ramsgate, and Hastings, and the climatic features of each were compared with those of London. The results of this discussion may be briefly summed up as follows, viz.:-The mean daily winter temperature of these seaside places, and especially of those situated on the coast of Devon and Scilly, is higher than at London; the mean daily maxima and minima are also higher, and especially the latter, so that the daily and montbly ranges of temperature are smaller; the mean humidity is less ; the general direction of the wind about the same; but the number of rainy days and the rainfall are greater at the seaside. As regards the wind, therefore, the chief point to be especially noticed is the amount of shelter afforded by high land, as at Ventnor, and especially of protection against the stormy and cold winds which ordinarily prevail at the end of February and in March. The soil, also, should be considered, as heavy rains at gravelly and chalky places are not so objectionable as on clayey ground. The discussion on this paper was adjourned until the next meeting, which was held on March 20th. 
drawn. He had seen the Dublin gravel-beds opened in a great many places, and more particularly in a gigantic way near the King's-bridge by Messrs. Guinness in order to obtain lime for their new buildings; and the gravel-stones so obtained were burned and yielded very good lime. Finglas, in every cholera epidemic, had been a focus of the disease; and it was situated on a gravel-bed. As to Dalkey, not only was the quarryhole used as a cesspool, but the water was drank by the miners; and that invariably spread the disease. Cholera was very virulent in Kingstown, which was situated on a granite district, although some of the granite was overlaid with boulder-clay. He deemed that the occurrence of isolated cases of cholera did not disprove the theory of contagion. They did not yet know anything about the incubation stage of cholera. Pettenkofer held that it was indefinite, and that cholera might be carried by a person who did not get the disease at all. It was pretty certain now that a person might swallow cholera contagion, carry it about, even bring it from the East, and not get it himself, and finally plant it in a gravel-bed where it would grow for somebody else. It was his intention at a future day to compare the paths of cholera in the country districts with the geological maps, when the Geological Surveys were sufficiently complete for the purpose. It had been shown by the reports of Cunningham and Lewis in India that those points were of considerable importance. Those gentlemen were still pursuing their inquiries. He believed that Pettenkofer had shown good grounds for his theory, and that it had been very much borne out by their experience in Dublin.

The Society then adjourned.

TREATMENT OF PARALYSIS IN POTT'S DISEASE.

Cauterisation of the back is advocated by Dr. Poore, of New York, in the treatment of cases of this class. He gives the following directions for its application, and if used accordingly there is, he states, no pain or subsequent suppuration:-1. The iron should be olive-pointed, and perfectly smooth; there must be no thin scales of oxidised metal on it, otherwise it will scratch the skin and make a sore. An iron with a platinum cap spun on has always a smooth surface, and does not oxidise. 2. The iron must be raised to a white heat; a lower temperature always gives pain, and makes a sore. 3 . In children the parts to be cauterised should be chilled with ice and the skin then wiped perfectly dry before applying the iron. 4. The iron must be simply brushed over the skin, so that after the operation there is only a whitish line to be seen. Dr. Poore has frequently cauterised the backs of children without their making any complaint; they have been put back in bed, and immediately returned to their toys as though nothing had been done.-N. Y. Med. Jour., Feb., 1878. 
an hour she gave birth to a small healthy female child; but on applying my hand to the abdomen I distinctly felt another in utero, and on examining, per vaginam, found a natural presentation. I now kept up firm pressure on the uterus for half an hour, but as no contraction ensued, I again resorted to electricity, with the same happy result, ruptured the membranes, and in a few minutes she gave birth to a small feeble male child, and in five minutes more a large single placenta came away (with both cords attached near the centre), leaving a firmly contracted uterus; but, remembering its previous relaxed state, I gave another hypodermic of ergot, although I could not say the first had had any effect; however, no hæmorrhage ensued, and up to the present (March 14th) mother and both children are doing well.

\section{TREATMENT OF ASTHMA BY IODIDE OF ETHYL.}

Ar a meeting of the Académie de Médecine on the 29th Jan., M. Sée made a communication on the employment of iodide of potassium and iodide of ethyl in asthma (Gaz. Méd. de Paris, Feb. 2). During the paroxysm the patient is given an inhalation of from five to ten drops of the iodide of ethyl. Immediately the dyspnœa disappears, and the respiration becomes easy and regular. In order to prevent return of the spasm, he prescribes, during the intervals, iodide of potassium in doses of from twenty-three to forty-five grains a day. M. Sée has found this plan of treatment most successful in twenty-four cases which he has watched for several years. The iodide of potassium and the iodide of ethyl do not appear to act so well in cases of asthma when given separately. They may also prove very beneficial in all other forms of dyspnoa, whatever the cause. M. Rabuteau (Gaz. Hebdom., 15 Fév.) has communicated to the Société de Biologie (Séance du 9 Fév.) the results of his experiments with the iodide of ethyl, the new remedy employed by M. Sée in the treatment of asthma. He finds that it is an anæsthetic, and that its action is less rapid than that of chloroform, but more prolonged. After inhaling the iodide of ethyl himself, he found iodine in notable quantity in lis urine-in fact, it is one of the richest substances in iodine. It is decomposed in the system into iodide of sodium and alcohol, according to the following formula:$\mathrm{C}_{9} \mathrm{H}_{8} \mathrm{I}+\mathrm{NaHO}=\mathrm{NaI}+\mathrm{C}_{2} \mathrm{H}_{6} \mathrm{O}$. 